\title{
Study on English Textbook Publication from the Perspective of Chinese Culture "Go Out"
}

\author{
Yu Wen \\ Shenyang Pharmaceutical University Foreign Department, Shenyang, Liaoning, China \\ viweny11@126.com
}

Keywords: Chinese culture going out, English textbooks, textbook publication.

\begin{abstract}
Textbook publication has a distinct social and contemporary nature. Under the strategy of Chinese culture 'go out', college English textbook publication should take the initiative to adapt to the national strategy, enrich their cultural connotations, and target to nurture a global awareness in the students. This paper analyzes the problems in the concept, orientation and content of college English textbooks from the perspective of going out of Chinese culture and puts forward corresponding exploratory countermeasures.
\end{abstract}

\section{“中国文化走出去” 视域下的大学英语教材的出版研究 \\ 于雯 \\ 沈阳药科大学社科文体学院外语部, 沈阳, 辽宁, 中国 \\ viweny11@126.com}

关键词：中国文化走出去; 英语教材；教材出版

中文摘要. 教材的编写和出版带有鲜明的社会性和时代性。在 “中国文化走出去” 的战略背景 下, 大学英语教材应该主动适应国家战略, 丰富自身文化内涵, 以培养学贯中西、能有效进 行跨文化沟通的优秀国际化人才为目标。本文从 “中国文化走出去” 的视角分析了大学英语 教材在出版理念、导向和内容配置方面存在的问题，并提出了相应的探索性对策。

\section{1. 引言}

一直以来，我国的外语教育与社会政治经济发展及教育政策变化密切相关，大学外语教 材的编写出版也受到本族文化传统和社会文化潮流的影响而带有鲜明的社会性和时代性。改 革开放以来, 在以 “引进来” 为主的发展战略影响下, 我国已经成功融入国际社会, 从当初 迎接全球化挑战到如今开始引领世界潮流。在这一阶段, 大学外语教育为国家经济社会发展 培养了大批外语人才，为引进国外先进技术以及吸收国外优秀文化思想做出了巨大贡献。随 着国家综合国力的提升与中外交流层次的深入, 党的十八届三中全会明确指出要 “扩大对外 文化交流, 加强国际传播能力和对外话语体系建设, 推动中华文化走向世界。”2015年, 我 国又提出了丝绸之路经济带和 21 世纪海上丝绸之路的倡议，简称 “一带一路”。从 “文化走 出去”与 “一带一路” 战略规划可以看出, 深层次的国际交流融合已经成为国家战略的关键 思想。而实现国与国之间深层次交流, 做到民心相通, 则需要大学外语教育培养出集语言技 能和文化素养为一体的国际化人才, 将中国的优秀文化继承并发扬出去。由于英语是国际通 用性语言, 也是我国学习人数最多的一门外语, 还是高等教育阶段的一门必修课。大学英语 
教学的成功与否对外语人才的培养质量有着关键性影响。英语教材是实现大学英语教学目标 的重要材料和手段,也是学生语言能力提高和文化知识建构的基本材料和重要依托。因此, “文 化走出去” 战略的思想内涵能否在大学英语教材上得到准确理解与体现, 直接影响着学生的 跨文化沟通能力和中外文化素养的培养。这种现实要求对于传统上以语言为导向的大学英语 教材的编写出版是一种切切实实的挑战。本文立足于在 “中国文化走出去” 大背景下，分析 当前大学英语教材在出版理念、出版导向和内容配置等方面存在的问题并提出相应的解决策 略。

\section{2. 从 “文化走出去” 战略看大学英语教材出版的现状}

\section{1 “工具化” 出版理念使得教材出版重 “语言” 而轻 “文化”}

在我国, 大学英语一直被定义为基础英语, 是一门帮助学生打好语言基础的通用性课程。 其教学重点往往在于语言教学本身, 主要针对词汇、语法、句法等语言知识的讲解, 并以培 养大学生的语言能力和听说读写等语言技能为主要目标。这种工具性和实用性取向直接影响 了大学英语教材出版理念, 教材出版也秉承着重语言知识和技能培养的宗旨, 服务于语言教 学。这种现象直接导致了大学英语教材中语言与文化本应相辅相成的关系在实际教学中失衡, 教材在实质上沦为了语言技能和知识获取的操练工具。以《新视野读写教程》为例, 虽然已 经过多次改版, 然而教材各单元的教学活动设计并没有发生本质上的变化, 仍然延续着单词 列表、课文阅读及配套练习的编排模式。教师和学生在教材的指引下也往往重复着单词讲解、 课文分析、做练习对答案等语言技巧训练, 教材的文化内容多为补充和注释性的, 文字简单, 浮于表面, 未能将人文精神彻底渗透, 贯穿教材始终, 因而师生很容易忽视其中的文化教育 部分。

\section{2 缺乏明确导向使得教材的中国文化内容编排零散，缺乏系统性}

教学大纲是一个国家或地区教学的“指挥棒，教材的编写、教学内容的设计和教学方法的 选择、教学计划的制定等无一不受其制定的教学目标所制约。作为大学英语教学指引的《大 学英语教学指南》已经开始考虑并逐步加强对文化知识素养及价值观教育的引导。如2007版 的《大学英语教学指南》已经提到“设计大学英语课程时也应当充分考虑对学生的文化素质培 养和国际文化知识的传授” [1]。2014年《大学英语教学指南》进一步将跨文化交际的要求单独 列为一节, 并明确指出“培养学生的跨文化交际意识和交际能力, 帮助学生了解中外的不同的 价值观世界观思维方式等差异”[2]。从教学大纲的上述变化可以看出, 对文化教学的要求已发 生根本性转变,将单向输入式的“国际文化知识”修改为双向交流式的“中外价值观, 世界观和思 维方式”，强调了在英语教学中传播中国文化的历史性任务。

但进一步分析都会发现,这些要求仍显得较为宽泛,没有在教学方法、内容、任务等方面进 行详细描述, 更没有明确指出在大学英语教材中如何合理增加中国文化的比重。缺乏具体明 确的指导原则和实施方法对大学英语教材中文化内容的编写造成了很多不利影响, 更不用说 相关的约束和评价机制的缺失了。因此尽管某些英语教材为了靠近教学大纲指令而增加了中 国文化内容, 然而内容的组织编排往往缺乏系统性, 大多呈零散分布, 且多以辅助英语教学 为目的; 中国文化的选材也多以说明性和介绍性为主, 涉及思想层面的文化材料, 如价值观、 伦理道德、思维模式等十分稀少。而且, 在中国文化内容方面, 当前已经有些大学英语教材 在编纂时有所考量, 但其内容往往千篇一律, 所涉及的中国文化内容仍然以中国传统文化及 其价值观为主, 甚至关注点还停留在“四大发明”与孔子等基本的历史要素上, 对于当代中国 社会进步的时代性特点完全没有涉及，这实际上也体现了对 “中国文化走出去” 策略的理解 不深。

此外, 辅助教学的材料如相关的有声资料、视频资料, 权威的参考资料都没有得到足够 重视, 缺乏立体化, 数字化配套建设。 


\section{3 跨文化交际的误读导致教材文化内容配置失衡}

众所周知, 跨文化交际是一种双向交流, 兼具有目的语文化输入与母语文化输出的双向 过程。这就要求学习者除了要对外国文化有所了解, 还要能用目的语正确地表达本国文化。 然而, 目前已出版的各类英语教材普遍存在西方文化为主, 中国文化边缘化的现象。具体表 现为, 大学英语教材在编写时, 为了保持语言输入的纯正性, 在选材上大都选取西方文化的 语言材料, 而有关中国题材 (特别是文化题材) 的文章并不多见, 有些教材甚至因此标榜自 己的 “原汁原味”。可见，中西方文化内容配置不当是大学英语教材文化内容失衡问题的一 个重要体现。

其次，纵观英语教材中的西方文化内容选材，绝大部分选自英美作家作品或与英美文化 有关的语言材料。英美文化内容十分强势, 而对于其他英语国家, 如加拿大、澳大利亚等, 其国别文化内容与中国本国文化内容面临的情况类似，都没有得到足够重视。这种相对单一 的选材方式实际上强化了以英美为主的西方文化的认同，而弱化了对整体英语文化的认知。 毕竟, “文化走出去” 的对象并非仅限于英美等主要西方国家。西方文化本身内容配置不当 是大学英语教材文化内容失衡问题的又一个重要体现。

这两方面问题共同作用的结果就是，学生在使用英语谈论英美等主要西方国家文化时可 以㑆㑆而谈, 而在介绍其他英语国家文化, 以及中国本国文化时, 显得捉襟见肘, 乏善可陈。 显然，这样的教材使用效果十分不利于“中国文化走出去”的民族大计。

\section{3. “文化走出去”战略下的大学英语教材出版策略}

基于以上当前大学英语教材存在的问题，本文将从导向、内容、形式三个方面对大学英 语教材的出版提出策略。

\section{1要主动适应国家发展战略弘扬中国文化}

“教材话语与社会政治因素、文化构建与传播的关系密切”[3]。自改革开放以来, 在以“引 进来” 为主的发展策略中，大学英语教材很好地服务于以传授语言知识和语言技能为目标的 大学英语通用教育, 在短短几十年内培养了大批满足通用性沟通和交流的人才。然而, 随着 近年来国家发展战略的调整，当前的出版教材已不能满足 “走出去” 战略背景下国家外语能 力建设和大学英语教育的转变。作为大学生语言能力提高和文化知识建构的主要学习资源, 大学英语教材的出版应该主动适应中国走向世界的外语战略导向, 审时度势, 调整出版策略, 修改教材内容，服务于 “中国文化走出去” 的大局。2014年新指南的出版，终于使得教材调 整在指导方针上有据可循。新指南不仅提出兼顾工具性和人文性, 还特别提出要帮助学生了 解中外不同的价值观、世界观、思维方式等差异。新版指南的最大变化就体现在 “中外” 二 字上, 即要求学生不仅了解目的语的文化观念, 更要了解母语文化, 在差异中学习和思考不 同文化价值。这就要求大学英语教材在设计编纂上, 一方面以学生外语学习需求为基础, 合 理选配英语国家的文化素材，另一方面编撰有关中国文化的权威英语材料，两者进行合理搭 配。同时, 在内容设置上要侧重中外文化对比研究, 体现差异性, 以便帮助学生从批判性的 视角来学习理解中外文化不同的内容、思想和价值观。更重要的是, 大学英语教材的编写者 要仔细研读中国文化走出去的内涵。我们今天要 “走出去” 的中国文化远不止几千年前的灿 烂文化。在科技日新月异，新事物新思想层出不穷的 21 世纪当代中国，建立在农业文明基础 上的中国传统文化并不能代表当代中国人所秉持的价值观念。“中国文化” 的完整内涵不仅 限于中国传统文化还应当涵盖 “当代中国的文化，即面向现代化面向世界面向未来的、民族 的科学的大众的社会主义文化” [4]。因此, 具有鲜明的社会性和时代性特征的大学英语教材, 应该与时俱进, 恰当地体现中国文化的时代性和新颖性, 使中国文化内容在大学英语教材中 呈现完整的文化体系, 做到中国优秀的传统文化要传承, 中国当代的全新文化面貌也要展现。 只有由内到外塑造好中国文化的形象，才能在完整的意义上实现 “中国文化走出去”。 


\section{2要合理配置多元文化比例切忌厚此薄彼}

一直以来, 英语教学者和学习者乃至英语教材都将英语文化定义为英美国家文化。其实, 英语文化不仅仅包含着英国和美国这两个国家的文化。根据Kachru的研究，英语按其分布还 可分为 “内圈英语国家” 和 “外圈英语国家” 两个不同的文化体系，前者如：加拿大、澳大利 亚、新西兰等主要为英联邦国家，后者包括新加坡、印度、牙买加等英语为官方语言的国家 [3]。“中国文化走出去” 的对象也不仅限于英美国家，也包含了 “一带一路” 沿途很多以英语 为官方语言的国家。因此, 大学英语教材里面外国文化内容的选材应适当扩大, 将加拿大, 澳大利亚、新西兰的英语内圈文化和新加坡、印度等国家的外圈文化内容都适当选取编入教 材，与中国文化内容一起，向学生展示一个“饱满的”文化王国，扩大中国学生对英语国家文 化的认知范围, 拓展其文化视阈, 真正实现站在全球化的高度来了解中外文化的差异, 促进 中外文化的融会贯通。

\section{3要加强数字化配套建设，形成全面完善教材体系}

从广义来讲, 教材不仅包括课堂教学的教科书, 还包括学生在学习中可能用到的各类学 习材料和教学资源。随着信息技术和移动技术的迅猛发展, 教材出版形式早已不局限于纸质 教材了。以“课件、网络课程、网络视听材料、音像制品以及教学资源库、试题库和练习题库” 等各种形式出版的数字化教材应运而生。但由于目前中国文化内容在英文教材中的设置比例 较少, 形式表现更为单一, 数字化教材的配套建设也没有跟上时代的步伐 ${ }^{[5]}$ 。殊知, 在教材中 增加中国文化内容并不简单意味着增加几篇相应的文章或练习, 而是需要大量的数字化资源 与之相配套。因此, 在未来的大学英语教材出版中要格外注重数字化教材的开发与建设。在 建设数字教材时, 为了培养学生的中国情怀和国际视野, 数字化内容的建设要涵盖多元文化, 在纸质教材无法呈现的内容可以数字化资源的形式作为学生自主学习的有益补充。多模态、 可视化、智能化、便捷化、碎片化的数字资源也更符合成长在数字年代大学生的需求。与英 语文化数字资源不同，涉及中国文化的内容的英文材料较少，且以纸质材料为主，制作精美 的音频视频资源远不如英语文化的呈现形式丰富，制作精美。以往情况下，教师会自发在网 络上搜罗相关的视频、音频资料作为教学补充材料，但是，相关的材料不易获得，即使找到 内容也往往不尽人意, 缺乏权威性。大学英语教材在出版时, 应集合中国文化和英语文化专 家一同开发数字化资源，提高中国文化的资源的权威的和准确性。

\section{4. 结束语}

大学英语教材在出版时, 应集合中国文化和英语文化专家一同开发数字化资源, 提高中 国文化的资源的权威的和准确性。

\section{References}

[1] Department of Higher Education of Ministry of Education. College English Teaching Requirements [M]. Tsinghua University Press, 2007.

[2] Wang Shouren. Interpretation of Key Points of College English Teaching Guide [J]. Foreign Language Community, 2016(3):2-10.

[3] Liu Yanhong, Lawrence Jun Zhang, Stephen May. A cultural study of College English textbooks based on the national planning corpus of College English textbooks [J]. Foreign Language Community, 2015(6):85-93.

[4] Fan Xiaofeng, Guo Fengzhi. Reflections on the Cultural Confidence of Socialism with Chinese Characteristics [J]. Research on Ideological Education, 2016 (7): 33-37. 
[5] Zhao Jun, Ge Shuhui. Thoughts on the Construction of Digital Publishing of College English Textbooks [J]. A Vast View on Publishing, 2016(14):77-79. 